\title{
Tratamento cirúrgico das feridas complexas
}

\section{Surgical treatment of complex wounds}

\author{
Nuberto Teixeira Neto', Alex $\mathrm{Chi}^{2}$, André Oliveira Paggiaro ${ }^{3}$, Marcus Castro Ferreira ${ }^{4}$
}

\begin{abstract}
Teixeira Neto N, Chi A, Paggiaro AO, Ferreira MC. Tratamento cirúrgico das feridas complexas. Rev Med (São Paulo). 2010 jul.-dez.;89(3/4):147-52.

RESUMO: O tratamento cirúrgico das feridas inclui uma série de procedimentos que vão desde o desbridamento até os procedimentos complexos como a utilização de retalhos livres utilizando técnicas microcirurgicas. Muitas vezes o tratamento cirúrgico é indispensável para o fechamento de uma ferida crônica ou uma ferida complexa. Estes procedimentos incluem a avaliação pré operatória adequada e a decisão de qual tipo de cobertura vai ser utilizado, podendo ser enxertos, retalhos locais ou retalhos livres.
\end{abstract}

DESCRITORES: Ferimentos e lesões/cirurgia; Ferimentos e lesões/diagnóstico; Úlcera cutânea/ cirurgia.

A s feridas complexas são as que mais frequentemente necessitam de tratamento cirúrgico. Cada tipo de ferida possui algum tipo de especificidade, que dependendo da sua fisiopatologia, interfere no tratamento. Apesar disto, alguns preceitos são comuns para o tratamento cirúrgico de todo tipo de ferida: desbridamento da ferida, osteotomias (em úlceras por pressão) para redução de proeminências ósseas, procedimentos que permitam o planejamento do fechamento definitivo da ferida.
Para escolha do tratamento cirúrgico das feridas complexas pode-se escolher entre dois paradigmas na cirurgia plástica reparadora, a escada reconstrutiva e o triângulo reconstrutivo. $\mathrm{Na}$ teoria da escada opta-se pela solução mais simples para resolução do caso podendo prosseguir para a mais complexa, caso não se resolva com a primeira opção. As opções cirúrgicas, da mais simples à mais complexa, são o fechamento primário, enxerto de pele, retalho local e retalho microcirúrgico.

\footnotetext{
1. Médico Residente de Cirurgia Plástica da Faculdade de Medicina da Universidade de São Paulo (FMUSP).

2. Acadêmico de Medicina da Faculdade de Medicina da Universidade de São Paulo (FMUSP).

3. Médico Assistente, Divisão de Cirurgia Plástica e Queimaduras do Hospital das Clínicas da Faculdade de Medicina da Universidade de São Paulo (HCFMUSP).

4. Prof. Titular da Disciplina de Cirurgia Plástica, da Faculdade de Medicina da Universidade de São Paulo (FMUSP).

Endereço para correspondência: Nuberto Teixeira Neto. Laboratório de Investigação Médica (LIM 04). Av. Dr. Arnaldo, 455 - SI. 1363 - São Paulo, SP, Brasil - CEP: 01246-903.
} 


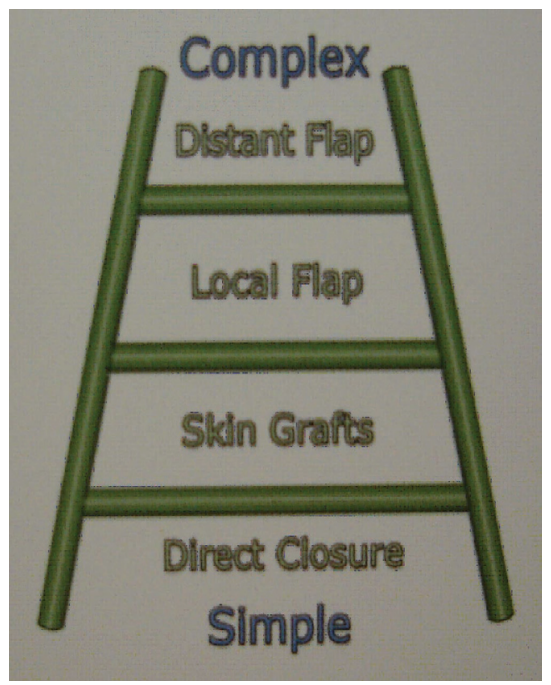

Atualmente, com o avanço da cirurgia reconstrutiva e a disponibilidade de técnicas mais sofisticadas, o modelo mais utilizado é o triângulo reconstrutivo, em que a técnica cirúrgica escolhida baseia-se na qualidade antecipada do resultado final. A escolha do procedimento é a melhor opção para manter a forma e a função da área a ser reconstruída, contanto que se mantenha a segurança do procedimento para o paciente, não sendo mais a complexidade do procedimento o limitante para se atingir o melhor resultado. As técnicas incluídas neste conceito são os retalhos locais, expansores e os retalhos livres.

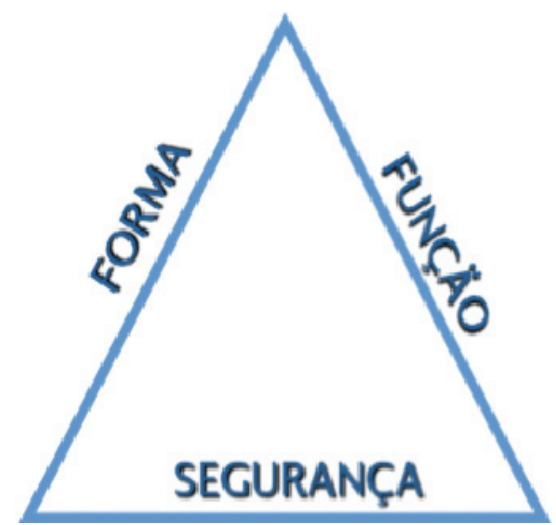

O aspecto mais importante no tratamento das feridas complexas é a abordagem adequada apesar de muitas vezes agressiva. A reconstrução para fechamento da ferida deve ser realizada assim que o leito da ferida estiver adequado para receber uma cobertura'.

Nas feridas complexas deve-se avaliar os fatores locais e sistêmicos da ferida, assim como a condição do paciente, determinantes para o sucesso do tratamento ${ }^{3}$.

Fatores locais incluem a profundidade (tecidos acometidos), edema local, estabilidade esquelética, irrigação sanguínea, presença de infecção bacteriana e qualidade do leito receptor.

Entre os fatores sistêmicos estão o status cardiovascular e pulmonar, status imunológico, condições crônicas debilitantes, diabetes e tabagismo. Sem duvida uma das avaliações sistêmicas mais importantes é determinar se alguma patologia sistêmica do paciente é a própria causa da ferida ${ }^{6}$.

Os fatores locais podem ser agudos ( $p$. ex: trauma, infecção) ou crônicos (ex: osteomielite crônica, insuficiência vascular) ${ }^{5}$.

O tratamento cirúrgico inclui procedimentos prévios e preparatórios para o fechamento definitivo da ferida.

\section{Desbridamento da ferida}

É o procedimento cirúrgico empregado para remoção de tecidos necróticos, desvitalizados e sujidades. Nas feridas crônicas deve-se realizar a limpeza do leito da ferida e preparo do mesmo para receber o fechamento definitivo. Este preparo pode ser conseguido clinicamente contanto que a contaminação e a necrose da lesão não tenham características que obriguem a realização de um debridamento cirúrgico, o qual deve ser feito idealmente com todos os cuidados de assepsia, luz e material adequado ${ }^{4}$.

Um desbridamento eficaz é o fator mais importante para o preparo de um leito, quando todo material necrótico deve ser removido até que se encontre tecido sangrante, bem irrigado. A remoção excessiva é desnecessária. Qualquer corpo estranho deve ser retirado da ferida assim como tecidos sem porejamento de sangue também dever ser ressecados, como qualquer tecido sem vitalidade, seja o músculo que não sangra ou seja osso necrótico.

Em pacientes com celulite, erisipela, abscesso ou outro tipo de infecção de partes moles adjacente, é desaconselhável o fechamento primário da lesão. Neste tipo de situação, além de cultura da ferida emprega-se atualmente a terapia por pressão negativa (vácuo) e antibioticoterapia apropriada ${ }^{2}$.

O sucesso do fechamento de uma ferida complexa depende de um desbridamento bem realizado, com a retirada de todo o material necrótico e infectado. Se esta primeira etapa do tratamento for bem sucedida, as chances de integração de enxerto de pele ou adequação de retalhos cutâneos são maiores, e o índice de deiscência e recidiva de lesões cai consideravelmente. 
Teixeira Neto N, et al. Tratamento cirúrgico das feridas complexas.

\section{Ostectomias}

São a retirada de fragmentos ou porções ósseas que devem ser indicadas quando houver infecção ou quando há proeminência óssea causando a ferida (úlcera por pressão). A ostectomia radical deve ser evitada, pois pode causar problemas adicionais como excessivo sangramento, instabilidade do esqueleto e redistribuição da pressão para pontos adjacentes.

Em úlceras de pressão, a ressecção de proeminências ósseas é parte importante do tratamento. Em úlceras isquiáticas, há muita controvérsia sobre o tipo de ostectomia que deve ser realizada. Alguns autores preconizam a isquiectomia total unilateral. Embora a taxa de recorrência se reduza, ficando entre 38 a $3 \%$, há chance aumentada de formação de nova úlcera contralateral. Em casos em que são realizadas isquiectomia bilateral, a redistribuição de pressão pode provocar úlceras perineais, com risco de formação de fístulas uretrais ${ }^{8}$.

\section{Fechamento definitivo}

Além de promover a proteção da área ulcerada, a resolução das feridas complexas reduz a perda protéica pela ferida, previne a sepse e a osteomielite, melhora a higiene, permite a reahiblitação social do doente e reduz os custos e o tempo de tratamento dos pacientes com feridas crônicas ${ }^{7}$.

O fechamento da ferida deve ser realizado o mais breve possível naqueles doentes que apresentem condições clínicas para realizar o procedimento cirúrgico e o leito da ferida esteja apropriado.

Ao estabelecer a programação cirúrgica, o cirurgião deve planejar a cobertura que seja a mais estável possível, utilizando a melhor técnica para aquele local. Também deve levar em conta a possibilidade de ulcerações futuras, buscando preservar alternativas para novos procedimentos de fechamento. As principais opções do cirurgião plástico são os enxertos de pele, retalhos locais (cutâneos, fasciocutâneos ou musculocutâneos) e os retalhos livres ${ }^{1}$.

A escolha entre as diversas opções deve levar em conta a localização, as dimensões e profundidade da úlcera bem como se procedimentos prévios já foram realizados. A área doadora de enxertos de pele deve ser adequadamente tratada para evitar a criação de uma nova lesão. As suturas devem ser mantidas sem tensão e deve-se evitar linha de sutura em pontos de apoio.

A - enxerto de pele é a transferência de espessura total ou parcial de pele de área doadora a distância para o leito receptor da ferida. A pele a ser transferida não leva consigo pedículo vascular e por isso sua viabilidade somente será assegurada se houver suprimento sanguíneo no leito receptor. A nutrição é dada por difusão no leito receptor, enquanto não se restabelece a circulação, este é o chamado período de embebição, o qual dura de 24 a 48 horas após a enxertia. A fim de se possibilitar maior chance de sucesso à enxertia devemos salientar a importância de se obter um leito receptor com vascularização adequada, tecido de granulação viável e curativo apropriado para promover melhor integração do enxerto à área receptora. Após 48 horas, inicia-se o crescimento de vasos sanguíneos vindos do leito da ferida e a irrigação sanguínea assim como a nutrição do enxerto é feita através dos condutores vasculares estabelecidos entre enxerto e leito. A fase de inosculação é aquela em que os vasos do leito e do enxerto alinham-se. Por fim, inicia-se a fase de neovascularização, formando novos capilares e novos vasos linfáticos ${ }^{10}$.

\section{Classificação dos enxertos}

Os enxertos de pele podem ser divididos segundo o doador e pela espessura:

\section{Doador}

Autógeno: quando o doador e receptor são o mesmo individuo.

Alógeno: quando o doador e receptor são indivíduos diferentes, porém, da mesma espécie.

Xenógeno: quando o doador e receptor são de espécies diferentes.

\section{Espessura}

Espessura parcial ou enxerto de pele parcial: aqueles que contem epiderme e parte da derme.

Espessura total ou enxerto de pele total: aqueles que englobam a epiderme e a totalidade da derme - camada papilar e reticular. 
As principais técnicas utilizadas para aplicação do enxerto são o enxerto em lâmina ou o enxerto em malha.

Os enxertos em lâmina ou selo são enxertos de pele em fragmentos, sem cortes ou orifícios, utilizados para reparar áreas que necessitem de melhor aspecto estético ou que necessite evitar a retração após a integração do enxerto, como em articulações, a retração também esta ligada à espessura do enxerto.

O enxerto em malha consiste na realização de pequenos cortes em toda extensão do enxerto de pele, possibilitando o aumento de superfície. Esta técnica tem grande valor em pacientes cuja área doadora é escassa, como nos grandes queimados, além de ter melhor integração aos leitos pouco vascularizado.

Os enxertos de pele total oferecem uma cobertura mais resistente, são menos sujeitos a contração secundária e necessitam de leito com rico aporte vascular. Seu uso, porém, fica restrito a pequenos traumas pela exigüidade da área doadora. Já os enxertos de pele parcial, podem ser aplicados em caráter definitivo ou temporário. Os enxertos de pele parcial proporcionam uma cobertura menos resistente com maior risco de retração secundária, porém toleram leitos menos vascularizados. Além disso, quando usadas para substituir mucosas sofrem metaplasia do epitélio, adquirindo aspecto semelhante à mucosa ${ }^{10}$.

Quanto a área doadora de enxerto de pele total a escolha dependerá de três fatores - tipo de enxerto, extensão e localização do defeito. Quanto mais próximo for a área doadora do leito receptor, melhor será o resultado estético pela semelhança entre os tecidos. Para o enxerto de pele total, as áreas doadoras são as regiões retroauricular, supraclavicular, inguinal e infraumbilical. O fechamento primário da área doadora é a técnica habitual.

Enxerto de pele parcial: as lesões extensas devem ser recobertas com enxerto de pele parcial que podem ser obtidas de diversas partes do corpo, preferencialmente das regiões com bom apoio ósseo, cuja retirada é mais fácil. As áreas doadoras comuns para este enxerto são as coxas, dorso, braço, tórax, nádegas e o couro cabeludo. A retirada do enxerto pode ser feita com o uso de facas manuais (faca de Blair), dermátomo manual ou dermátomo elétrico ${ }^{9}$.

O leito receptor deve estar limpo, sem infecção e bem vascularizado, evidenciado por uma granulação firme, viva e plana.

Tratamento da área doadora após retirada de enxertos de pele parcial a área doadora é tratada, em nosso serviço com curativos oclusivos com filme transparente, os quais dificilmente necessitam ser trocados. A área receptora é mantida fechada pelos curativos por três a sete dias a fim de se prevenir a interrupção das delicadas conexões vasculares que se desenvolvem nesse período. Até o décimo dia o enxerto ainda é muito frágil, devendo-se prevenir a distribuição de forças entre enxerto e seu leito subjacente para evitar a interrupção da neovascularização e perda do enxerto. A utilização de terapia por pressão negativa aumenta a chance de integração dos enxertos de pele. As principais complicações que levam a perda do enxerto são a formação de hematoma, infecção e seroma. Quando há formação de tecido de granulação exuberante, deve ser removido por raspagem para diminuir a flora bacteriana e nivelar o leito.

B - retalhos consistem em tecido mobilizado, contudo mantendo-se ligado ao seu pedículo vascular que mantem sua irrigação.

Em relação ao tipo de vascularização, os retalhos podem ser ao acaso ou axial (quando são irrigados por múltiplos vasos de pequeno calibre). Em relação à composição podem ser cutâneo, muscular, miocutâneo, fasciocutâneo, osteomiocutâneo, entre outros.

Os retalhos cutâneos são irrigados na pele por plexo ao nível da fáscia superficial e enviam ramos perpendiculares à pele para formar o plexo dermosubdérmico. Admite-se que o comprimento do retalho ao acaso não depende da largura da pele mantida, mas sim do calibre e número de artérias perfurantes contidas no pedículo.

Esses retalhos podem ser elevados a fim de prover pele e tecido subcutâneo viável para o fechamento de uma ferida adjacente.

As limitações do retalho ao acaso são o arco de rotação e proximidade com a área lesada. Em geral, feridas complexas que não aceitem enxertos pela deficiência vascular no leito, apresentarão injúria no tecido adjacente não estando indicado retalho ao acaso.

O retalho axial é baseado em uma ou mais artérias que constituem o eixo (pedículo) do retalho e tem sua vascularização conhecida. $O$ número dessas artérias é limitado e o calibre possibilita esqueletização do pedículo para uso em ilha ou para transferência com técnica microcirúrgica. $\mathrm{O}$ comprimento do retalho axial será o comprimento da artéria somado a um retalho ao acaso, pois as ramificações da artéria axial terminam no plexo dermo-subdérmico que representa a ultima estação vascular dos retalhos.

Os músculos superficiais apresentam excelente suprimento vascular e dão importante 
contribuição ao suprimento sanguíneo da pele através dos vasos perfurantes. Podem ser utilizados como retalhos baseado em seu pedículo vascular dominante. As dimensões dos retalhos musculares ou miocutâneos correspondem a dimensão do músculo e sua respectiva ilha de pele.

Os retalhos musculares e miocutâneos são mais efetivos para cobertura de feridas com suspeita de infecção (especialmente nas osteomielites), em feridas extensas e profundas. Entre as desvantagens desse retalho estão o risco de gerar deformidade e perda funcional na área doadora assim como atrofia muscular no pós-operatório.

O retalho fasciocutâneo fornece uma fonte de tecido confiável, possui adequado suprimento vascular, cobertura durável, menor potencial de deformidade funcional e reconstrução com aspecto anatômico mais próximo ao original. A ampla aceitação e a aplicação deste retalho se devem sobretudo à facilidade de dissecção, menor volume retirado da área doadora e menor volume oferecido à área receptora fornecendo segurança quanto à vascularização. Podem ser transferidos a distância se a revascularização for feita por técnica microcirúrgica de sua artéria e veia. Está indicado principalmente quando há exposição de ossos, articulações e tendões, retrações cicatriciais, úlceras de perna, seqüelas de mastectomia e ressecções tumorais. Estes retalhos fornecem menor volume, portanto, não servem para defeitos muito extensos.

Os retalhos microcirúrgicos (livres) são aqueles em que se realiza a transferência de tecidos de um local para outro a distância utilizando-se a técnica microcirúrgica para anastomose dos vasos do pedículo deste retalho nos vasos receptores. $O$ tecido é retirado de uma área do corpo em que a seqüela na área doadora seja menor que o benefício que este tecido promoverá na área receptora. Este tipo de procedimento é possibilitado quando o retalho pode sobreviver somente com suprimento sanguíneo do pedículo, geralmente, uma artéria e uma veia ${ }^{10}$.

Nas feridas com exposição de tecidos nobres, normalmente com tamanho maior que $6 \mathrm{~cm}$ e sem retalhos locais seguros disponíveis, os retalhos livres são a principal escolha para cobertura da lesão. Geralmente, os ferimentos com este tipo de característica localizam-se principalmente em região distal da perna, causados por trauma, insuficiência vascular, tumores e diabetes.

Diversas áreas doadoras de retalho livre foram descritas. A escolha do local doador deve considerar diversos fatores, entre eles, o tamanho da zona doadora, tipo de ferimento, comprimento do pedículo e seqüela na área doadora.

Em feridas crônicas com leito de aspecto fibrótico e pouco vascularizado, ao se transferir microcirurgicamente um tecido, este parece aumentar a vascularização do tecido da ferida ao redor do retalho. Este fenômeno parece ocorrer pela formação de novas interconexões vasculares, talvez pela liberação de fatores de crescimento locais.

Recentemente, o surgimento de terapia por pressão negativa têm melhorado a chance de cura de lesão complexa. Seu uso melhora as condições do leito receptor facilitando a integração do tecido transplantado ao local receptor ${ }^{11,12}$.

Apesar da complexidade para realização dos retalhos livres e da necessidade de infra-estrutura com moderna tecnologia, o transplante de tecidos por microcirurgia estabeleceu nova dinâmica no tratamento de feridas complexas, possibilitando o fechamento de lesões de grande dimensão com localização desfavorável.

O custo do tratamento cirúrgico das feridas pode ser alto, mas a médio e longo prazo o retorno do investimento é rapidamente recuperado, pois reduz os gastos com curativos, possibilita recuperação mais precoce e, em alguns casos, reinsere mais rapidamente o indivíduo ao mercado de trabalho e à sua vida social.

Teixeira Neto N, Chi A, Paggiaro AO, Ferreira MC. Surgical treatment of complex wounds. Rev Med (São Paulo). 2010 jul.-dez.;89(3/4):147-52.

ABSTRACT: Surgical treatment of the wounds includes a variety of procedures ranging from débridement to complex procedures such as use of free flaps using microsurgical techniques. Often surgery is important for closing of a chronic wound or a complex wound. These procedures include preoperative evaluation and proper decision on which type of coverage will be used that may be grafts, local flaps or free flaps.

KEY WORDS: Wounds and injuries/surgery; Wounds and injuries/diagnosis; Skin ulcer/ surgery. 


\section{REFERÊNCIAS}

1. Caldwell MD. Wound surgery. Surg Clin North Am. 2010;90(6):1125-32.

2. Warriner R, Burrell R. Infection and the chronic wound: a focus on silver. Adv Skin Wound Care. 2005;18(Suppl 1):2-12.

3. Park H, Copeland C, Henry S, Barbul A. Complex wounds and their management. Surg Clin North Am. 2010;90(6):1181-94.

4. Attinger CE, Janis JE, Steinberg J, Schwartz J, Al-Attar A, Couch K. Clinical approach to wounds: débridement and wound bed preparation including the use of dressings and wound-healing adjuvants. Plast Reconstr Surg. 2006;117(7 Suppl):72S-109S.

5. Lee CK, Hansen SL. Management of acute wounds. Surg Clin North Am. 2009;89(3):659-76.

6. Ayello EA. What does the wound say? Why determining etiology is essential for appropriate wound care. Adv Skin Wound Care. 2005;18(2):98-109; quiz 110-1.
7. Degreef HJ. How to heal a wound fast. Dermatol Clin. 1998;16(2):365-75.

8. Jones KR, Fennie K. Factors influencing pressure ulcer healing in adults over 50: an exploratory study. J Am Med Dir Assoc. 2007;8(6):378-87.

9. EBHARDT K. Problems of wound surgery and plastic surgery in medium-sized hospital. Medizinische. 1956;7(33-34):1134-6.

10. Mathes SJ, Nahai F. Reconstructive surgery principles, anatomy, \& technique. Edinburgh: Churchill Livingstone; 1997. v.1, Chap. 2, 3, 4.

11. Ferreira MC, Wada A, Tuma Jr P. The vacuum assisted closure of complex wounds: report of 3 cases. Rev Hosp Clin Fac Med Sao Paulo. 2003;58:227-30.

12. Ferreira MC, Carvalho VF, Kamamoto F, Tuma P Jr, Paggiaro AO. Negative pressure therapy (vacuum) for wound bed preparation among diabetic patients. Sao Paulo Med J. 2009;127:166-70. 